\title{
O QUE EU OLHO NÃO ME VÊ, OU O PROBLEMA DA REPRESENTAÇÃO DO SUBALTERNO: O NARRADOR EM $A$ RESISTÊNCIA, DE JULIÁN FUKS
}

\author{
Francieli Borges \\ Larissa Garay Neves
}

Submetido em 30 de maio de 2018.

Aceito para publicação em 25 de outubro de 2018.

Cadernos do IL, Porto Alegre, n. ${ }^{\circ}$ 57, novembro. p. 79-89

\section{POLÍTICA DE DIREITO AUTORAL}

Autores que publicam nesta revista concordam com os seguintes termos:

(a) Os autores mantêm os direitos autorais e concedem à revista o direito de primeira publicação, com o trabalho simultaneamente licenciado sob a Creative Commons Attribution License, permitindo o compartilhamento do trabalho com reconhecimento da autoria do trabalho e publicação inicial nesta revista.

(b) Os autores têm autorização para assumir contratos adicionais separadamente, para distribuição não exclusiva da versão do trabalho publicada nesta revista (ex.: publicar em repositório institucional ou como capítulo de livro), com reconhecimento de autoria e publicação inicial nesta revista.

(c) Os autores têm permissão e são estimulados a publicar e distribuir seu trabalho online (ex.: em repositórios institucionais ou na sua página pessoal) a qualquer ponto antes ou durante o processo editorial, já que isso pode gerar alterações produtivas, bem como aumentar o impacto e a citação do trabalho publicado.

(d) Os autores estão conscientes de que a revista não se responsabiliza pela solicitação ou pelo pagamento de direitos autorais referentes às imagens incorporadas ao artigo. A obtenção de autorização para a publicação de imagens, de autoria do próprio autor do artigo ou de terceiros, é de responsabilidade do autor. Por esta razão, para todos os artigos que contenham imagens, o autor deve ter uma autorização do uso da imagem, sem qualquer ônus financeiro para os Cadernos do IL.

\section{POLÍTICA DE ACESSO LIVRE}

Esta revista oferece acesso livre imediato ao seu conteúdo, seguindo o princípio de que disponibilizar gratuitamente o conhecimento científico ao público proporciona sua democratização.

http://seer.ufrgs.br/cadernosdoil/index

Quinta-feira, 22 de novembro de 2018. 


\title{
O QUE EU OLHO NÃO ME VÊ, OU O PROBLEMA DA REPRESENTAÇÃO DO SUBALTERNO: O NARRADOR EM A RESISTẾNCIA, DE JULIÁN FUKS
}

\author{
WHAT I LOOK DOES NOT SEE ME, OR THE PROBLEM \\ OF REPRESENTATION OF THE SUBALTERN: THE \\ NARRATOR IN A RESISTÊNCIA, BY JULIÁN FUKS
}

\author{
Francieli Borges ${ }^{21}$ \\ Larissa Garay Neves ${ }^{22}$
}

\begin{abstract}
RESUMO: Aqui verificamos o romance A Resistência, de Julián Fuks, nos limites e possibilidades do modo como é narrado. Isso porque o narrador é também a principal personagem, mesmo que objetive dar foco à história do irmão adotivo. Tal análise se justifica na medida em que temos um romance em primeira pessoa - permeado de tentativas de reconstituição de um passado equívoco. Essa escolha formal na estruturação do texto suscita diversas questões sobre a confiabilidade dos relatos apresentados, assim como possíveis marcas de silenciamento no que tange à representação do irmão adotado. Portanto, observamos as escolhas formais que imperam na obra; e afora isso, em que medida resistir se configura, dentro do espaço temático, como algo relativo a uma conciliação com o passado do irmão adotado ou do passado daquele que conta a história. Para tanto, consideramos, primeiramente, os aspectos gerais que permeiam a questão da violência, para, então, tratarmos de suas manifestações mais sutis no que tange à apresentação da história pelo narrador.
\end{abstract}

PALAVRAS-CHAVE: romance; narrador; Julián Fuks; A Resistência.

ABSTRACT: We propose here an analysis of the novel A Resistência, by Julián Fuks, in regard to its limits and possibilities concerning the narrative voice. This approach is due to the fact that the narrator is, also, the main character of the narrative, even though his interest lies in telling his adoptive brother's story. Since we have a narrative presented in the first person that is permeated with reminiscences and sometimes obscure attempts of reconstitution of an inaccurate past, our focus of analysis is coherent. The formal choice made by Fuks brings up several questions regarding the reliability of the events that are presented to the readers, as well as possible signs of silencing when it comes to the representation of the adopted brother by the narrator. Therefore, we analyze the main formal choices made in this text; and how the act of resisting configures, in this fictional text, something related to a conciliation with the past of the adopted brother or of the one who tells the story. For this purpose, firstly we investigate the general aspects that surround the matter of violence, so that we can deal with its subtler expressions in the text concerning the presentation of the story by the narrator.

KEYWORDS: novel; narrator; Julián Fuks; A Resistência.

Isto não é uma história. Isto é história. Julián Fuks, A Resistência

\section{Primeiras Palavras}

\footnotetext{
${ }^{21}$ Doutoranda em Estudos Literários na Universidade Federal de Santa Maria. Bolsista CAPES. Mestra em Educação pela Universidade Federal de Pelotas. francielidborges@gmail.com

22 Doutoranda em Estudos Literários na Universidade Federal de Santa Maria. Bolsista CAPES. Mestra em Estudos Literários pela Universidade Federal de Santa Maria. larissa-garay@hotmail.com
} 
Julián Fuks é um dos escritores de maior destaque da Literatura Brasileira contemporânea. Aos trinta e sete anos, Fuks, pertencente a uma família de exilados argentinos, recebeu dois prêmios de renome incontornável: um Prêmio Jabuti, talvez um dos mais importantes atribuídos àqueles que se aventuram no âmbito da escrita e, em especial, da ficção, em 2016; e, recentemente, em 2017, o Prêmio Literário José Saramago. Ambas as láureas foram concedidas ao escritor paulistano por seu romance $A$ Resistência, publicado em 2015.

A Resistência tem um título bastante propício. Isso porque no plano temático a resistência - enquanto significado que sugere uma série de condutas e, em certo sentido, dá um norte ao leitor e à leitora - surge a todo momento e se entrecruza em inúmeras situações, quer seja entre as personagens, quer seja na insistente reflexão do narrador sobre o poder da linguagem em mudar a perspectiva do que se quer contar. Esse modo de apresentar o assunto, em uma coleção de espirais, tinha tudo para transformar o livro em um emaranhado de temáticas truncadas e comprometer o andamento da locução destinada a ele. No entanto, o que ocorre é o exato oposto, de forma que poucas vezes, na contemporaneidade, uma obra brasileira soube alinhar tão bem forma e conteúdo.

O romance explora as possibilidades de compreender os acontecimentos de uma família em torno de um ponto em comum, o exílio. Em um tom de memória, o narrador menciona os episódios e decisões de um casal com postura política atenta e que se vê acuado pela ditadura brutal da Argentina, durante a segunda metade do século XX. A partir daí a narrativa apresenta as questões que envolvem as dificuldades, nessa conjuntura, de fixar residência em outro país, nesse caso o Brasil, também ele sob o signo de uma ditadura civil-militar. Em um outro plano, com o foco mais direcionado, o narrador atenta a objetos do cotidiano, a fotografias, a toda sorte de coleções materiais que formam uma memória familiar, e se demora em fazer uma espécie de biografia imaginária do irmão, adotado sob circunstâncias históricas tão nebulosas. É nessa personagem, principalmente, que o romance se detém, também para pensar os limites entre a ficção, a realidade, a história oficial, o tempo, a violência em inúmeras nuances.

Nossa hipótese é que nessa condição surge um modo narrativo que se enlaça, em um primeiro momento referencialmente, em relação de diálogo com situações anteriormente mencionadas; e então, no formato de uma autoconsciência subjetiva que se sobressai. O narrador de A Resistência incorre em observações projetadas a partir das próprias dúvidas sobre o passado da família, especialmente do irmão, e é nessa estratégia que o texto flui.

Assim, nosso objetivo consiste em analisar o narrador-personagem desse romance, que munido apenas de rememorações na tentativa de contar a história de seu irmão e de sua família exilada, incorre em diversas questões ambíguas, típicas de relatos testemunhais. Dessa forma, argumentamos que na tentativa de narrar a violência sofrida por sua família e, principalmente, os problemas enfrentados por seu irmão adotivo, o narrador também silencia aquele cuja história, em princípio, seria contada. Isto é, a estrutura formal do romance, através da figura do narrador, de certo modo, cria uma atmosfera de violência velada na forma como o irmão - adotado e subalterno nessa família - é representado.

\section{O narrador que quer fazer ver: violência e seus enlaces}

A Resistência, além do título que apresenta referência direta a um dos principais temas encontrados no romance, resiste, também, no plano da forma. A linguagem com a 
qual Julián Fuks arquiteta sua história é, ao mesmo tempo, fugaz e potente, porque organizada em capítulos curtos, que lembram memórias passageiras que não podem ser alcançadas em sua totalidade. Há, por outro lado, capítulos tão intensos no que diz respeito à estrutura formal que reforçam a incessante busca do narrador-personagem por seu próprio passado e o de seu irmão adotivo. Os capítulos de abertura são, na verdade, aos quais nos referimos, aqui, ao tratar da curiosa relação entre forma e tema nesse romance:

\begin{abstract}
Não quero imaginar um galpão amplo, gélido, sombrio, o silêncio asseverado pela mudez de um menino franzino. Não quero imaginar a mão robusta que o agarra pelas panturrilhas, os tapas ríspidos que o atingem até que ressoe seu choro aflito. Não quero imaginar a estridência desse choro, o desespero do menino em seu primeiro sopro, o anseio pelo colo de quem o receba: um colo que não lhe será servido. Não quero imaginar os braços estendidos de uma mãe em agonia, mais um pranto abafado pelo estrondo de botas contra o piso, botas que partem e o levam consigo: some a criança, resta a amplidão do galpão, resta o vazio. Não quero imaginar um filho como uma mulher em ruína. Prefiro deixar que essas imagens se dissipem no inaudito dos pesadelos, pesadelos que me habitam ou que habitaram uma cama vizinha à minha. (FUKS, 2015, p. 11)
\end{abstract}

O fragmento acima, parágrafo de abertura do segundo capítulo, exemplifica de modo interessante a hipótese apresentada nesse estudo. $\mathrm{O}$ narrador, ao imaginar como teriam sido os primeiros momentos da vida de seu irmão adotivo, apresenta ao leitor uma descrição pavorosa e, por certo, angustiante de ser rememorada: um cenário permeado por imagens lúgubres, que têm por objetivo transmitir a dor de uma criança sem família, além do desespero de uma mãe. Assim, o uso sistemático de "não quero imaginar" reforçam a temática da história, já que causam o efeito duplo de uma luta constante contra a própria mente e imaginação, incapaz de ser domada apenas pela vontade; e, ainda, remetem a uma respiração ofegante, característica de momentos de sufocamento. Além disso, o narrador argumenta que prefere deixar que essas imagens sejam dissipadas pelos pesadelos, fato que demonstra o caráter nebuloso dessas memórias.

Por isso, é possível argumentar que a violência é trazida à tona, também, a partir da própria forma ficcional. Isto é, o narrador-personagem desta história, desde os primeiros capítulos, está em um entremeio, não só entre uma reconciliação com seu passado e presente, mas, inclusive, no modo com que transmite ao leitor - sua principal testemunha - a sua história. Desse modo, cabe considerarmos, de forma mais cuidadosa, algumas noções de violência que perpassarão a voz narrativa desse romance.

A frase que começa o capítulo sete fica no entrelugar de uma espécie de confissão do narrador que está atento à necessidade da literatura e, ao mesmo tempo, à insuficiência dela. Em "Isto não é uma história. Isto é história. Isto é história e, no entanto, quase tudo o que eu tenho ao meu dispor é a memória, noções fugazes de dias tão remotos (...)" (FUKS, 2015, p. 23), vivemos o jogo das singularidades espaçotemporais evocadas por toda ficção que procura abordar os aspectos caros à passagem do tempo, seus eventos marcadamente brutais, mas, ainda, e talvez principalmente, daquelas lacunas melhor percebidas por indivíduos em seu cotidiano. Como cercar a ausência, ou o vazio deixado por essas circunstâncias? O narrador está ciente dessa problemática, que antes de tudo, é o motor da narrativa - a dificuldade de estabelecer figurações mais ou menos cotidianas sob o signo da história, aquela, com letra maiúscula que costumamos ver em compêndios oficiais. 
Estar atento à maneira como se conta algo e se a história ali está bem contemplada é uma preocupação muito pertinente, especialmente se o tema a ser relatado envolve situações violentas. A definição primeira de violência que guia nossas leituras é aquela presente no Dicionário de Política (2007), de Norberto Bobbio et al., sobre a qual se diz que violência é uma intervenção física, voluntária - ou seja, com a intenção de ofender, destruir, coagir -, de um sujeito ou várias pessoas junto a um indivíduo ou grupo. De uma primeira explicação aparentemente simples, o dicionário fornece outras possibilidades para pensar a violência em categorias: quando infringida por outrem; quando direta, com ataque ao corpo, por exemplo, ou também no caso de ser indireta, como nas situações em que as pessoas são privadas de meios básicos para sobreviver.

A violência, ainda, de acordo com o dicionário sobredito, é diferente do poder: contudo, com as incursões sobre o mesmo tema em Tratado Sobre a Violência (2006), de Wolfgang Sofsky, conforme veremos, essa distância fica mais difícil de delimitar. Se no dicionário está advertido que a violência, embora se desdobre em várias formas, não pode ser um termo aplicado sem critérios, no que tange à parte da obra sobre a conceituação de Violência e Poder Político, no entanto, vemos que as máscaras que ela utiliza devem ser especificamente nomeadas e reconhecidas, principalmente porque ela ganha ares de legitimidade quando utilizada com a força do Estado. Especificar tais formas de violência - e desembocar em como se daria a resistência a elas - é importante porque elas têm flagrante presença no romance que estudamos.

Uma das primeiras manifestações da violência é a necessidade de essa família se exilar, motivados pela perseguição política. Essa fuga, esse ato imposto pela força, é uma reflexão que vai e vem no texto, de maneira que a personagem principal, quando retorna à Argentina para procurar mais vestígios sobre o próprio passado e o do irmão, pensa nas marcas do presente, isto é, se "estará também a perseguição política submetida às normas de hereditariedade?" (FUKS, 2015, p. 19). Ora, a violência constitui o corpo social, de sorte que os Governos a utilizam em perseguições para os mais diversos fins - isso porque acontecem as repressões (na forma oficial das polícias e/ou exército) mesmo com a finalidade de manter uma coexistência pacífica e impedir os meios de violência "ilegítima". Perguntar-nos sobre seus vincos, no cotidiano tarefa do narrador a que atentamos - é incontornável.

Ainda porque a violência, nessa forma, sempre tem sua razão de ser a partir de um nível de consenso do meio social. Em linhas gerais, há a violência punitiva e a violência terrorista dos modos de governar, essa segunda diferente porque não visa apenas a punição, mas também gerar o medo constante em qualquer forma de estar no mundo que seja desviante e é, por esse motivo, paralisante, justamente porque mais ou menos imprevisível - e aqui é possível enquadrar inúmeros governos totalitários da modernidade. Nesse último modelo de governar, há poucas saídas para os sujeitos, isto é, é possível ser a vítima ou então ser o carrasco, como se vê na narrativa de Fuks: "De Buenos Aires meus pais foram expulsos quando ele não somava nem seis meses de idade, de Buenos Aires nos sentíamos todos alijados enquanto não lhes permitiam retornar (...)" (FUKS, 2015, p. 18).

A violência é, também, espetacular, uma vez que serve para propagandear e provocar o medo ou a reação, especialmente com a difusão dos meios de comunicação em massa. Nesse sentido, atos violentamente brutais ou indiscriminados comumente são técnicas mais complexas de atingir diversos fins políticos, como a coesão de grupos específicos. Por outro lado, porém, se pensarmos no lugar de opositor, mas com semelhante pano de fundo, é aí também que o narrador se insere, ao alegar que é "fillho orgulhoso de um guerrilheiro de esquerda e isso em parte me justifica, isso redime 
minha própria inércia, isso me insere precariamente numa linhagem de inconformistas." (FUKS, 2015, p. 38).

Nós, os leitores, somos envolvidos nos tentáculos do que parece ser uma irremediável violência intrínseca a tudo como conhecemos. Sob essas circunstâncias, entendemos que a opressão e a arbitrariedade, assim como o medo constante, passam a ser gerais, como no caso do desaparecimento da colega de trabalho da mãe do narrador, Marta Brea. A situação causa perplexidade e, ao mesmo tempo, sentimento de estagnação frente à realidade que se concretiza: não se pode lutar, ainda que isso seja o correto a ser feito - calar e se afastar é uma necessidade, um jeito de sobreviver.

Esse "bem supremo", a sociedade cristalina, que através da coerção seria responsável por eliminar a rebeldia e a inconstância, manteve as pessoas sob a presença constante da morte, alimentando o temor a ela - daí provinha o próprio poder. Esse olho vigilante, a utopia da ordem, aspirava à completa eliminação da liberdade (SOFSKY, 2006, p. 18). A descendente direta do poder ordenador, para o estudioso supracitado, é a tortura, que também faz parte da história da família desse romance. No caso do sequestro de Marta Brea, por exemplo, o leitor testemunha os horrores enfrentados por aqueles que ousavam se opor à ordem vigente:

\begin{abstract}
A última vez que minha mãe ouviu sua voz foi numa reunião do conselho diretivo, enquanto debatiam problemas menores, e alguns minutos depois, reunião interrompida por alguém que a chamava para uma consulta rápida, a estridência inesperada de seus gritos atravessando os corredores, varando as paredes, percutindo os tímpanos e a memória de quem ali aguardava sua volta. Correndo até a entrada do hospital, minha mãe ainda pôde testemunhar a brusquidão com que a empurravam e a enfiavam num carro sem placa, a partida súbita e singular daquele carro se repetindo tantas vezes ante seus olhos (FUKS, 2015, p. 76).
\end{abstract}

Ainda, a violência também é aquela presente na ditadura da consciência. Nesse sentido, o medo, a repressão interior, sempre constante, é um sintoma_- a cultura exige sem cessar o esforço, o trabalho, a adaptação e a submissão, ou seja, mais violência a partir do desejo de suprimir o sofrimento que nasce na esperança da eternidade. Aqui se justificaria a motivação de romancear uma passagem familiar, tantas vezes problemática, em meio a tantos embates da consciência narrativa, como vimos em $A$ Resistência.

Se pensarmos na tentativa de recriar a história para escapar da condição histórica a que as pessoas estão sujeitas, a cultura atuaria como um corpo (ou ficção) social para obedecer a uma necessidade de perpetuação, de revisão constante, atuaria, em suma, como atenuante das condições reais. Adiante na nossa interpretação, nos vemos às voltas com pensamentos sobre os motivos pelos quais vivemos intervalos de paz, sempre episódicos. Talvez seja simplesmente porque não se pode viver permanentemente em guerra.

Caminhar por esses bosques conceituais, por obras como a de Fuks, propiciam um alerta: a violência nunca desaparece, ela apenas muda de rosto. Observar essas nuances e sutilezas é muito importante no trabalho de crítica literária, uma vez que os autores e autoras são seres sociais. De qual forma pode haver um aspecto estético ou mesmo ético frisado em um texto literário? Para essa verificação, entender as formas da violência é imprescindível. Há outra de suas máscaras sobre a qual gostaríamos de nos debruçar a seguir: aquela que insiste em calar ao impedir o Outro de falar, de ter uma identidade, aquela violência presente em inúmeras instâncias da existência humana. 


\section{Um narrador voltado para si: questões de forma}

A Resistência, como já mencionado, diz muito a respeito do tema principal apresentado por Julián Fuks: trata-se de uma narrativa contra qualquer tipo de resignação, seja ela moral, psicológica, estética. $\mathrm{Na}$ verdade, as primeiras sentenças da narrativa dão o tom do que o leitor encontrará ao longo de toda a história:

\footnotetext{
Meu irmão é adotado, mas não posso e não quero dizer que meu irmão é adotado. Se digo assim, se pronuncio essa frase que por muito tempo cuidei de silenciar, reduzo meu irmão a uma condição categórica, a uma atribuição essencial: meu irmão é algo (...) (FUKS, 2015, p. 9).
}

Permeada por hesitações e incertezas, esse é um narrador típico em primeira pessoa, sobretudo daqueles romances com teor de rememoração. Tal fragmento é bastante interessante, uma vez que são essas as frases que iniciam a história e demarcam o grau de confiabilidade que pode ser atribuído a esse narrador. Apesar disso, uma narrativa em primeira pessoa suscita questões relacionadas a quão confiáveis são os relatos apresentados. Ocorre que na citação acima, o narrador transita entre a incerteza em afirmar que seu irmão é adotado e, ao mesmo tempo, a negação desse fato; curiosamente, entretanto, essa é a primeira informação apresentada ao leitor.

Ainda no mesmo parágrafo, o narrador retoma o fato de seu irmão ser adotado e explica o porquê de não gostar de tratar do assunto: "Meu irmão é adotado, mas não quero reforçar o estigma que a palavra evoca, o estigma que é a própria palavra convertida em caráter. Não quero aprofundar sua cicatriz e, se não quero, não posso dizer cicatriz" (FUKS, 2015, p. 9). Novamente, então, vemos o narrador imerso em contradição. Além disso, ele trata a adoção do irmão como uma cicatriz, como um estigma evocado pela própria palavra, sem que contextualize os motivos. Assim, apresentando julgamentos morais sobre o irmão, conforme vemos em outras passagens, ainda, ele diz mais do que qualquer outra coisa sobre si e sua dificuldade no relacionamento fraternal.

Essa postura, que a todo momento rememora acontecimentos passados, condiz com a proposta do romance como um todo. Se temos um narrador lutando com suas lembranças, como forma de compreender a violência de seu passado, para, talvez, encarar o presente, é verossímil o caráter ambíguo de suas afirmações. No entanto, é preciso atentar às contradições desse modo de contar:

Não posso fazer desse menino, do menino e do homem que ele é hoje, um personagem fácil. Não posso lhe atribuir uma dor qualquer, insensata, que o reduza a uma sensibilidade excessiva passível de piedade, que o submeta à comoção fácil. (FUKS, 2015, p. 24)

Ora, se o objetivo não é tornar a adoção do irmão um espetáculo - ou, então, representá-lo de forma duvidosa - o efeito é justamente o oposto. Há, ao longo de narrativa, constante reafirmação da personalidade do irmão sob prismas que não temos como confirmar (também nós, leitores, suscetíveis a diversos afetos). Tal constatação é feita através da voz narrativa e, nunca, através da voz do próprio irmão. Assim, Fuks traz uma questão especialmente pertinente aos estudos da memória: o problema de reforçar posicionamentos a priori indesejados ao tentar explicar certas condições. No caso do narrador, sua insistência em tentar compreender os acontecimentos pregressos da sua vida familiar surte efeito contrário e, ainda, parece reforçar o sentimento de não pertencimento do irmão adotado.

Essa possibilidade de interpretação advém das declarações do próprio narrador: 
Não são poucos os indícios de que ele soube de fato esquecer, embora esquecer não seja a palavra exata - recalcar é a palavra que meus pais indicarão aqui, posso prever. Não são poucas as evidências de que ele passa longos períodos sem admitir sequer para si, sem aceitar ou reconhecer - dias ou meses, talvez anos, trancado em seu quarto sem que nada disso se aposse dele, sem que retorne à sua mente tudo o que eu não quero e não posso dizer, tudo o que eu preciso dizer. E ele não precisa dizer para si? (FUKS, 2015, p. 15 - 16)

Ao leitor atento, a intensidade da ilusão proposta pelo narrador, no fragmento acima, parece ambígua, principalmente porque ele menciona apenas indícios ou evidências, mas em momento algum as exemplifica. Portanto, como este não é um narrador onisciente, é impossível saber exatamente o modo como seu irmão se sente, sobretudo porque o relacionamento entre eles é visivelmente distante. Nesse sentido, o interesse recai, novamente, em dificuldades próprias do narrador, e não de seu irmão.

$\mathrm{Na}$ medida em que a narrativa avança, o irmão é figurado de modo cada vez mais recluso, quase intratável. Se considerarmos os efeitos dessa representação, mais uma vez, então, o efeito é o - suposto - contrário do desejado pelo narrador: é ele quem cala o irmão porque assim o apresenta aos leitores: "tão largo era seu recolhimento, tão ressonante seu silêncio, que parecia ocupar o espaço inteiro e nos coagir também a calar." (FUKS, 2015, p. 30).

Dessa maneira, o leitor está diante de uma violência diferente de outras, porque ela não é explícita, mas ligada à estrutura do texto. De forma interessante, Fuks manipula a voz narrativa a assemelhar-se, num primeiro momento, a uma testemunha dos acontecimentos de uma família exilada. Contudo, uma leitura mais atenta do argumento prevê um posicionamento problemático à forma como o conjunto é apresentado, corroborado, também, pela passagem a seguir, em que o narrador rememora um momento de conflito entre ele e seu irmão e apela à emoção do leitor:

Meu irmão me expulsou do quarto, mas dizer que meu irmão me expulsou do quarto é inexato - não apenas distorcido, mas quase oposto à realidade. Não pediu que eu saísse ou me lançou ao corredor; segurou-me pelo braço e me conduziu no sentido contrário, quarto adentro, até a porta que se abria para a sacada. Atirou-me, assim, na noite - uma noite fria, é o que dita a memória com seus pendores dramáticos - e me trancou lá fora, atrás da porta de vidro, a porta alta que devia ter o dobro do meu tamanho, o dobro da minha idade, aquela imensa vidraça. (FUKS, 2015, p. 48)

Aqui há questões relacionadas a um apelo quase tendencioso. A esse respeito, Wayne Booth é bastante elucidativo:

Quando se modelam ações humanas para fazer uma obra de arte, a forma
conseguida nunca pode divorciar-se do significado humano, incluindo os
juízos morais que estão implícitos sempre que os seres humanos agem. E
nada do que o escritor faz pode ser compreendido, em última análise,
isolado do seu esforço de o tornar acessível a alguém - os seus iguais, ele
próprio como leitor imaginado ou a audiência. (BOOTH, 1983, p. 397)
(Tradução nossa)

\footnotetext{
${ }^{23}$ When human actions are formed to make an art work, the form that is made can never be divorced from the human meanings, including the moral judgments that are implicit whenever human beings act. And nothing the writer does can be finally understood in isolation from his effort to make it all accessible to someone else - his peers, himself as imagined reader, his audience (BOOTH, 1983, p. 397).
} 
Ou seja, conforme temos insistido ao longo dessa breve análise, julgamos o irmão adotado com base nessa espécie de informação. Não se deve perder de vista, que em maior ou menor grau, o filtro desse narrador também é permeado por emoções, traumas, reminiscências. Como deve proceder o leitor, então, visto que a única informação que nos chega é através de um narrador controverso?

Outros indícios de sua conduta discutível são encontrados na passagem a seguir, que contradizem as informações sobre o parto do irmão adotivo, anteriormente apresentadas:

\begin{abstract}
O parto eu não posso inventar, do parto nada se sabe. Pondero agora, passadas tantas páginas, que deveria ter sido fiel ao impulso de suprimir aqueles pobres cenários imaginários, que deveria ter cedido à hesitação e calado sobre esse acontecimento insondável. Não foi assim, não foi narrável, o nascimento do meu irmão. O quarto branco ou o opressivo pavilhão, o som de botas contra o piso ou as mãos doutas em inspeção, basta, já chega, são todas ficções descartáveis, são meras deturpações. Que baixe os braços a mulher que os estendia em desrazão, a mulher e sua ruína, cultivadas contra toda expectativa em minha mente infértil. Que se ignore também o menino, o menino e seu desabrigo, o menino e sua salvação, aquele menino que também não era meu irmão. $\mathrm{O}$ parto eu não posso inventar, repito, do parto não há informação. (FUKS, 2015, p. 59)
\end{abstract}

Aqui o narrador assume o caráter memorialístico, mas principalmente, ele reconhece que muito do que é dito foi imaginado antes de qualquer comprovação. Nesse sentido, é importante que pensemos nos lugares em que se situam as colocações das personagens, assim como no lugar ocupado pelo narrador.

Gayatri Chakravorty Spivak, renomada crítica literária, discorre de modo excepcional sobre este tema em seu ensaio Pode o subalterno falar?, publicado, no Brasil, em 2010. Segundo Spivak, "nenhum ato de resistência pode ocorrer em nome do subalterno sem que esse ato esteja imbricado no discurso hegemônico" (SPIVAK, 2010, p. 12). Assim, caminhamos em direção à assertiva que prevê que o narrador se apropria da história de seu irmão como forma de reconciliação com seu passado. Isso se apresenta, entretanto, de forma problemática, porque o irmão não é figurado com falas ou réplicas, mas de maneira indireta pelo narrador.

$\mathrm{Na}$ análise de Spivak, há uma relação intrínseca entre o "falar por" e o "representar", pois, em ambos os casos, a representação é um ato de fala em que há a pressuposição de um falante e um ouvinte. A autora argumenta ainda que

\footnotetext{
o processo de fala se caracteriza por uma posição discursiva, uma transação entre falante e ouvinte e, nesse sentido, conclui afirmando que esse espaço dialógico de interação não se concretiza jamais para o sujeito subalterno que, desinvestido de qualquer forma de agenciamento, de fato, não pode falar. (SPIVAK, 2010, p. 13)
}

Posto dessa forma, em A Resistência não há espaço dialógico de interação entre o irmão, o subalterno, portanto, e os outros familiares. Na verdade, há inclusive um desvio no modo como a aparência física desse irmão adotado é apresentada ao leitor. Segundo o narrador, seu irmão estava "magro demais" e, mesmo que ciente de que as palavras distorcem, ele continua a descrevê-lo como alguém passível de pena por sua aparência enfraquecida: 
Não quero, não posso fazer do meu irmão um artista da fome. Não quero descrever um rosto pálido, ou costelas salientes a esgarçar uma cicatriz, como se inventasse um personagem qualquer para um novo livro, na forja de mais um espetáculo assombroso e triste. (FUKS, 2015, p. 73)

Curiosamente, esse traquejo retórico de tentar não ter uma atitude justamente no momento em que ela está sendo afirmada, caracteriza ainda mais o caráter incerto e delicado em que a narrativa é tecida. Quer dizer, não é necessário argumentar que não pode e não quer tornar o irmão algo digno de espetáculo, porque a própria menção à sua aparência franzina contradiz essa proposta. Além disso, ao fim da narrativa, o leitor descobre que o narrador subvertera o sobrepeso de seu irmão em uma magreza que, se não apela ao leitor, pelo menos reforça o caráter escorregadio das ficções.

A narrativa se encaminha para o final com o mesmo tom denso e até melancólico do narrador:

Sem nenhuma sutileza me vejo a temer: talvez o erro seja este livro, criado para um destinatário inexistente. Volto à origem do meu ímpeto: queria, creio, que o livro fosse para ele, que em suas páginas falasse o que tantas vezes calei, que nele se redimissem tantos dos nossos silêncios. Não será assim, não foi assim, já consigo saber. Com este livro não serei capaz de tirálo do quarto - e como poderia, se para escrevê-lo eu mesmo me encerrei? (FUKS, 2015, p. 96)

Aqui ele alega saber que escreve seu próprio fracasso, já que seu objetivo não foi alcançado - a finalidade era, na verdade, uma reescrita possível do relacionamento entre ambos.

\section{Considerações Finais}

Chama atenção, em A Resistência, o forte caráter de crítica social e política, além da interessante organização formal por Fuks, especialmente no modo como o narrador apresenta sua fragmentada história ao leitor. É ao longo de toda a estrutura do texto que percebemos as tentativas do narrador em resistir às situações adversas, em narrar as violências sofridas por sua família e, ainda, de forma especialmente flagrante, em resistir a resignar-se a ter uma relação não solucionada com o irmão.

Nessa narrativa, o autor faz questão de nos apresentar a incerteza daquele que olha, mas não vê, ou pelo menos não vê tudo, já que é um narrador em primeira pessoa; e, por outro lado, aquele que não tem a possibilidade de ser visto. Uma vez que as escolhas formais são inteiramente ideológicas, sobretudo em um texto com temática tão delicada, cabe retomar algumas noções a respeito da figura do narrador.

Para elucidar melhor o nosso ponto, citamos Ansgar Nünning (2001), que apresenta uma discussão que abarca tanto o processo de focalização e narração da história a partir de uma única personagem - como é o caso do romance de Fuks -, a subjetividade das personagens imbricada nessa estrutura, bem como o relevante papel do leitor no processo de leitura. Para esse crítico literário, a escolha por uma forma de narração a partir da própria personagem representa, também, os diversos mundos, crenças e ideologias inerentes a qualquer experiência subjetiva. Por isso, é necessário atentar aos possíveis desvios no discurso ou, até mesmo, de graus de confiabilidade, no material narrado. No caso do narrador-personagem de A Resistência, nossa breve análise demonstra uma tentativa desesperada de reconciliação com uma memória dolorosa e, no entanto, necessária para essa personagem. Desse modo, Nünning (2001) 
é esclarecedor ao tratar sobre o que chama de "perspectiva estruturante" das narrativas, que é, ao fim e o cabo:

a soma de todos os modelos que ele ou ela construíram do mundo, dos outros
e dela/dele [da personagem que é também o/a narrador(a)]. Uma perspectiva
do personagem é governada pela totalidade do conhecimento do próprio
indivíduo e suas crenças, intenções, traços psicológicos, atitudes, posição
ideológica e sistema de normas e valores internalizados. ${ }^{24}$ (NÜNNING, 2001,
p. 211) (Tradução nossa).

Nünning (2001), então, traz à baila a questão ideológica que perpassa qualquer história e, no caso da ficção, é reforçada a partir das escolhas do autor. Ou seja, Julián Fuks enfatiza o efeito da violência sofrida pela família do narrador, assim como toda sorte de desgaste na relação entre irmãos, porque escolhe narrar a partir de uma única perspectiva. Além disso, os capítulos curtos e as constantes repetições sintáticas, a saber não quero dizer ou não quero imaginar, formam o elo perfeito para representar uma história que por si só já é fragmentada e imensamente penosa.

\section{REFERENCIAS}

BOBBIO, Norberto. et al. Dicionário de Política. Tradução de João Ferreira et al. Brasília: Ed. Univ. de Brasília, 13a ed., 2007. BOOTH, Wayne. The Rhetoric of Fiction. 2.ed. Chicago: Universtiy of Chicago Press, 1983.

FUKS, Julián. A Resistência. São Paulo: Companhia das Letras, 2015.

NÜNNING, Ansgar. On the perspective structure of narrative texts: steps toward a Constructivist Narratology. PEER, W. e CHATMAN, S. New perspectives on narrative perspective. New York: State University of New York Press, 2001. p. 207-223.

SOFSKY, Wolfgang. Tratado sobre la violencia. Madrid: Abada, 2006.

SPIVAK, Gayatri Chakravorty. C. Pode o subalterno falar? Tradução de Sandra Regina Goulart Almeida et al. Belo Horizonte: Editora UFMG, 2010.

\footnotetext{
24 the sum of all the models he or she has constructed of the world, of others, and of herself. A character-perspective is governed by the totality of an individual's knowledge and belief sets, intentions, psychological traits, attitudes, ideological stance, and system of values and norms that have been internalized. (NÜNNING, 2001, p. 211)
} 